\title{
APPLICATION OF SIMUS METHOD FOR ASSESSMENT ALTERNATIVE TRANSPORT POLICIES FOR CONTAINER CARRIAGE
}

\author{
Svetla Stoilova \\ Technical University - Sofia, Bulgaria \\ stoilova@tu-sofia.bg
}

\begin{abstract}
The purpose of this paper is to study the container transportation by rail and by road as alternative policies for carriage and to choose the effective one. A methodology to evaluate both transportation and ranking them has been developed. The Sequential Interactive Modelling for Urban Systems (SIMUS) as a tool to aid decision-making problems with multiple objectives has been applied. The methodology of the research includes two scenarios taking into account the weights of criteria - the first scenario does not use the weights of criteria and for the second one it is necessary to apply the weights which are pre-defined. The methodology of the research includes four steps. The first step defines the quantitative and qualitative criteria for assessment of container transportation. The investigated strategies for transportation that have been studied are intermodal rail transport and road transport. The weighs of criteria have been determined in the second step. They are used only in the second scenario. The third step of the research formulates the alternatives of carriage by containers and includes two ways of transportation: by container block trains and by trucks. The SIMUS method has been applied in the fourth step for ranking the variants of transportation. The method solves successive scenarios formulated as linear programming. This step involves ranking of alternatives and the choice of optimal type of transportation. The methodology is approbated for the routes Sofia-Varna from the railway and road network of Bulgaria. It was found that the technologies that include rail transport are the best variants of transportation. The methodology can be applied for assessment different types of transportation and different transport policies.
\end{abstract}

Keywords: SIMUS method, intermodal transport, rail, road, container.

\section{Introduction}

The intermodal transportation of containers includes carriage by different modes of transportation, for example, by rail and by road. An alternative policy for carriage by intermodal transport is transportation of containers by trucks, as road trains. Transportation between the start and the final point in many cases could be made by different types of carriage. This raises the question of choosing an optimal route and mode of transport.

Different methods are used to choose the optimal route for transportation. The model of route selection of container multimodal transport considering the carbon cost is elaborated in [1]. In [2] the authors presented an optimal-route selection model of container multimodal transport with the minimum transport cost as the objective function and also the colony algorithm is used.

The dynamic programming algorithm is proposed in [3] to determine the optimal strategy of transport modes. The rail, road and water transport have been investigated in this study. The transportation costs, total time of transport, transport quality are defined as a main factors of container transportation. The minimization of the generalized transport cost has been applied as the objective function. The objective function consists of the total transport cost from the starting point to the destination; the cost produced by the transhipment in transit city; the time value cost of the whole trade of the cargo; the punishment cost.

The profit maximization model elaborated in [4] uses mixed-integer programming container shipping service selection. The objective function minimizes the total cost, which includes the fixed costs for the selected services, the cost of transporting goods, and the penalties for unmet demand. In [5] a Geospatial Intermodal Freight Transportation (GIFT) model is presented which is developed through GIS platform. The model uses the cost, time and emission as objective functions. The highway, rail, and shipping networks, ports, railway yards, and other transfer facilities have been included in an integrated intermodal transportation network.

The containerized freight transport through the intermodal transport network of Peninsular Malaysia has been investigated in [6]. The authors elaborated a model to analyse the transport network based on ArcMap software and MatLab software. The optimum route and mode of transport from origin to destination for different objective functions such as the distance, time, emission and cost have been determined in the transport network of Malaysia. In [7] an optimization model has been elaborated based on integer linear programming for intermodal transportation route selection by taking 
into account carbon emissions and intermodal transfers. The problem of multi-modal transportation routing planning is investigated in [8]. A model based on bi-objective mixed integer linear programming with objective minimization of the total transportation cost and the total transportation time has been elaborated. The model uses Pareto optimality. In [9] the authors studied the problem of sustainable intermodal transportation. A mixed-integer-programming-based mathematical model has been elaborated to determine the allocation of containers to different transportation modes. The social and ecological risks of the transportation modes have been defined by using a fuzzy-based approach.

In [10] as key indicators in transport the factors transport cost, transport time, flexibility, reliability, quality and sustainability have been determined. In [11] the authors defined the criteria for assessment of the intermodal terminals - flexibility, safety and security, reliability, time, and accessibility. In [12] the authors defined the quality and performance indicators for intermodal terminals. In [13-15] the problems of railway and road transport have been investigated. In [15] the following criteria to assess the intermodal container transportation have been defined: the environmental criterion; operational costs for intermodal transportation; transportation fare; infrastructure charges; duration of transportation; transport from door to door; duration of transhipment operations; comfort; security; reliability; stability. The criteria have been determined by applying the DEMATEL method of multi-criteria analysis. In [16] a model is elaborated for routing by the criterion of the lowest cost and application of the graph theory. In [17] the theory of decision has been applied for route selection of a truck. The Analytic Hierarchy Process (AHP) method of multicriteria analysis has been used for best route prioritization and selection [18-20]. In [21] the queuing system or theory has been applied to study the freight transport in the checkpoints in Bulgaria. Intermodal transport has been studied also in [22-23].

It can be summarized that the transport costs and time are the main criteria of optimization. Two types of optimization are used - one by applying mathematical methods of optimization, and the other, which uses the methods of multi-criteria analysis.

SIMUS (Sequential Interactive Modelling for Urban Systems) is a hybrid method based on Liner programming, Weighed Sum Method (WSM) and Outranking. The criteria and objective function in the SIMUS method are equivalent linear functions. SIMUS was developed by Nolberto Munier, a researcher at the Valencia Polytechnic University, Spain, and tested in many and diverse types of projects [24-25].

The purpose of this paper is to elaborate a methodology for assessment the alternative transport policies for container carriage by using the SIMUS method for making decisions.

\section{Materials and methods}

The methodology for evaluating the effectiveness of intermodal transport includes the following steps.

1. Definition of quantitative and qualitative criteria for the assessment of container carriage. The following criteria defined in [15] are studied: S1: Environmental criterion; S2: Operational costs for intermodal transportation; S3: Transportation fare; S4: Infrastructure charges; S5: Duration of transportation; S6: Transport from door to door; S7: Duration of transhipment operations; S8: Comfort; S9: Security; S10: Reliability. This means meeting the deadline for the delivery of cargo and accurate schedule of trains; S11: Stability. This criterion takes into account the stability of transportation according to seasonal conditions.

2. Determining the weights of the criteria. This paper uses the weights of criteria that were determined by the author in [15] using the DEMATEL method.

3. Selection of variants of the container transportation for a given route. In this research intermodal rail transport and road transport are investigated.

4. Choice of optimal variant of transportation. The Sequential Interactive Modelling for Urban Systems (SIMUS) method has been applied in this step for ranking the variants of transportation. The method solves successive scenarios formulated as linear programming. It consists of the following steps.

- Build the 'Decision or Initial matrix' of the criteria and alternatives used as the starting point by all Multi-criteria Decision-Making methods. The matrix consists of two parts named 
respectively "Left Hand Side" (LHS) and "Right Hand Side" (RHS). The LHS part presents the values of criteria for the alternatives. The RHS part establishes the limits to each criterion.

- For each criterion the type of optimization is set.

- Calculation of the sum of scores in each row for all criteria

- Determination of the normalized values of each row. For this purpose the value of each element of the row is divided by the sum of the same row.

- Determination of the thresholds for each row. This value is determined according to the type of optimization. The value of thresholds is equal to the maximum normalized value of the row, when the objective of criterion is of maximum. When the type of optimization of the criterion is of minimum, the threshold value is equal to the minimum normalized value of the row. The thresholds represent the RHS part of the decision matrix.

- The procedure of the SIMUS method uses simplex algorithm of linear programming. The number of linear optimization models is equal to the number of criteria. SIMUS starts by using the first criterion as the objective function. For this purpose the first criterion is removed from the decision matrix. The other rows are considered as restrictive conditions of the linear model. Then, the procedure is repeated with the other criteria. The second objective function corresponds to the second criterion, etc. The procedure is repeated until all criteria are used as objective functions.

- The results of all linear optimization models are saved in a payoff matrix called Efficient Results Matrix (ERM). The values of the ERM matrix present the score of each alternative for each optimization model.

- Determination of the normalized Efficient Results Matrix. Any normalization system can be used, as total sum in the row, maximum value in the row, Euclidean formula and min-max. The choice of the normalization system does not affect the results of ranking the alternatives.

- Determination of the sum of all elements in each column (SC).

- Determination of the Participation Factor (PF). PF presents the number of participation of each alternative in each column of the normalized Efficient Results Matrix. This participation is used as a weight for alternatives.

- Normalization of the results of the Participation Factor in NPF. Normalization is made by dividing each value of PF by the total number of criteria.

- Determination of ERM ranking of alternatives. For this purpose NPF is multiplied by the column sum (SC) for each alternative. The maximal values of the criterion show the best alternative. The alternatives are ranking in descending order of the criterion.

- Determination of the squared Project Dominance Matrix (PDM). The number of columns and rows in this matrix is equal to the number of alternatives. In this stage the model finds the differences between the values in the same row of normalized ERM, starting from the highest value in the first row. The procedure is repeated with all the values. The matrix PDM presents the degree of dominates between the alternatives. Finally, the row sum and column sum of the matrix PDM are determined.

- Determination of PDM ranking of alternatives. For this purpose the net dominance is calculated as a difference between the row and column values for the same alternative. The maximal values of the criterion show the best alternative. The alternatives are ranking in descending order of the criterion.

- The ranking from ERM and from PDM are identical.

The methodology includes two scenarios taking into account the weights of criteria - the first scenario does not use the weights of criteria and for the second one it is necessary to apply the weights which are pre-defined.

\section{Results and discussion}

The methodology is approved for container transport by rail and road for direction Sofia - Varna. The following variants of transportation have been studied:

- variant 1 - Freight block train by direction Sofia-Gorna Oryahovitsa-Varna;

- variant 2 - Freight block train by direction Sofia-Karlovo-Karnobat-Varna; 
- variant 3 - Road train by direction Sofia-Veliko Tarnovo-Varna;

- variant 4 - Road train by direction Sofia-Plovdiv-Burgas-Varna;

- variant 5 - Road train by direction Sofia-Plovdiv-Karnobat-Shumen-Varna.

The variants 1 and 2 present transportation of containers by railway transport; the variants from 3 to 5 present carriage of containers by using road transport.

Two strategies of SIMUS application have been experimented. The first strategy does not use the weights of criteria, and the second one applies the weights of criteria in SIMUS optimization. The Software SIMUS System has been used to perform the research [26].

\section{Strategy 1}

Table 1 presents the initial decision matrix in part LHS data, the second part shows the type of optimization for each criterion, the respective operator, and the value of thresholds RHS that establishes the limits to each criterion. The values of the criteria for all variants are determined according to [27]. The value of RHS column is determined according the normalized values of each row. The sum in row is applied for normalization. Table 2 shows the normalized values of the LHS data.

Table 1

\section{Initial matrix}

\begin{tabular}{|c|c|c|c|c|c|c|c|c|}
\hline \multirow{2}{*}{ Criteria } & \multicolumn{9}{|c|}{ LHS Data } & \multicolumn{3}{c|}{ Thresholds } \\
\cline { 2 - 9 } & Variant 1 & Variant 2 & Variant 3 & Variant 4 & Variant 5 & Action & Operator & RHS \\
\hline S 1 & 238257.00 & 247250.00 & 442887.00 & 519189.00 & 545931.00 & $\min$ & $\geq$ & 0.12 \\
\hline S 2 & 263.76 & 254.48 & 379.00 & 454.44 & 378.00 & $\min$ & $\geq$ & 0.15 \\
\hline S 3 & 1.00 & 1.00 & 0.00 & 0.00 & 0.00 & min & $\geq$ & 0.00 \\
\hline S 4 & 167.33 & 158.39 & 12.41 & 12.41 & 12.41 & min & $\geq$ & 0.03 \\
\hline S 5 & 9.05 & 8.57 & 7.14 & 8.12 & 8.62 & $\min$ & $\geq$ & 0.17 \\
\hline S 6 & 1.00 & 1.00 & 1.00 & 1.00 & 1.00 & max & $\leq$ & 0.20 \\
\hline S 7 & 1.00 & 1.00 & 0.00 & 0.00 & 0.00 & $\min$ & $\geq$ & 0.00 \\
\hline S 8 & 1.00 & 1.00 & 1.00 & 1.00 & 1.00 & max & $\leq$ & 0.20 \\
\hline S 9 & 1.00 & 1.00 & 0.00 & 0.00 & 0.00 & max & $\leq$ & 0.50 \\
\hline S 10 & 1.00 & 1.00 & 0.00 & 0.00 & 0.00 & max & $\leq$ & 0.50 \\
\hline S 11 & 1.00 & 1.00 & 0.00 & 0.00 & 0.00 & $\max$ & $\leq$ & 0.50 \\
\hline
\end{tabular}

Table 2

Normalized "Sum" Matrix (LHS)

\begin{tabular}{|c|c|c|c|c|c|}
\hline Criteria & Variant 1 & Variant 2 & Variant 3 & Variant 4 & Variant 5 \\
\hline S 1 & 0.12 & 0.12 & 0.22 & 0.26 & 0.27 \\
\hline S 2 & 0.15 & 0.15 & 0.22 & 0.26 & 0.22 \\
\hline S 3 & 0.50 & 0.50 & 0.00 & 0.00 & 0.00 \\
\hline S 4 & 0.46 & 0.44 & 0.03 & 0.03 & 0.03 \\
\hline S 5 & 0.22 & 0.21 & 0.17 & 0.20 & 0.21 \\
\hline S 6 & 0.20 & 0.20 & 0.20 & 0.20 & 0.20 \\
\hline S 7 & 0.50 & 0.50 & 0.00 & 0.00 & 0.00 \\
\hline S 8 & 0.20 & 0.20 & 0.20 & 0.20 & 0.20 \\
\hline S 9 & 0.50 & 0.50 & 0.00 & 0.00 & 0.00 \\
\hline S 10 & 0.50 & 0.50 & 0.00 & 0.00 & 0.00 \\
\hline S 11 & 0.50 & 0.50 & 0.00 & 0.00 & 0.00 \\
\hline
\end{tabular}

Table 3 presents the results of the SIMUS procedure by applying simplex algorithm of the linear programming method. SIMUS starts by using the first criterion as the objective function, (formula 1). For this purpose the first criterion is removed from the decision matrix. The others rows are considered as restrictive conditions of the linear model, (formulas from 2 to 11). The liner model for the first criterion is as follow: 
- Objective function

$$
0.12 x_{1}+0.12 x_{2}+0.22 x_{3}+0.26 x_{4}+0.27 x_{5} \rightarrow \min
$$

- Restrictive conditions

$$
\begin{gathered}
0.15 x_{1}+0.15 x_{2}+0.22 x_{3}+0.26 x_{4}+0.22 x_{5} \geq 0.15 \\
0.50 x_{1}+0.50 x_{2} \geq 0.00 \\
0.46 x_{1}+0.44 x_{3}+0.03 x_{4}+0.03 x_{5}+0.03 x_{6} \geq 0.03 \\
0.22 x_{1}+0.21 x_{2}+0.17 x_{3}+0.20 x_{4}+0.21 x_{5} \geq 0.17 \\
0.20 x_{1}+0.20 x_{2}+0.20 x_{3}+0.20 x_{4}+0.20 x_{5} \leq 0.20 \\
0.50 x_{1}+0.50 x_{2} \geq 0.00 \\
0.20 x_{1}+0.20 x_{2}+0.20 x_{3}+0.20 x_{4}+0.20 x_{5} \leq 0.20 \\
0.50 x_{1}+0.50 x_{2} \leq 0.50 \\
0.50 x_{1}+0.50 x_{2} \leq 0.50 \\
0.50 x_{1}+0.50 x_{2} \leq 0.50
\end{gathered}
$$

where $x_{j}$ - score of each alternative;

$j=1, \ldots, m-$ number of variants.

The results for this optimization are recorded in the first row of the Efficient Results Matrix (ERM), Table 3.

Table 3

\section{Efficient Results Matrix (ERM)}

\begin{tabular}{|c|c|c|c|c|c|}
\hline Criteria & Variant 1 & Variant 2 & Variant 3 & Variant 4 & Variant 5 \\
\hline S 1 & 0.96 & 0.00 & 0.00 & 0.00 & 0.00 \\
\hline S 2 & 0.00 & 0.72 & 0.00 & 0.00 & 0.11 \\
\hline S 3 & 0.00 & 0.00 & 0.00 & 0.00 & 1.00 \\
\hline S 4 & 0.00 & 0.00 & 0.00 & 0.00 & 0.83 \\
\hline S 5 & 0.00 & 0.04 & 0.00 & 0.54 & 0.00 \\
\hline S 6 & 1.00 & 0.00 & 0.00 & 0.00 & 0.00 \\
\hline S 7 & 0.00 & 0.00 & 0.00 & 0.00 & 1.00 \\
\hline S 8 & 1.00 & 0.00 & 0.00 & 0.00 & 0.00 \\
\hline S 9 & 1.00 & 0.00 & 0.00 & 0.00 & 0.00 \\
\hline S 10 & 1.00 & 0.00 & 0.00 & 0.00 & 0.00 \\
\hline S 11 & 1.00 & 0.00 & 0.00 & 0.00 & 0.00 \\
\hline
\end{tabular}

Figure 1 presents the results of the Efficient Results Matrix. The results show that variant 1 has the score of 0.96 . The others variants are not a part of the solution. Their values are 0 . When the second criterion is applied as objective function, the variant 2 and variant 5 have a score different from zero. The optimizations by the third and fourth criteria show that the variant 5 has a score 1 . The results show that the variant 2 and variant 4 have a score different from zero, when the fifth criterion is used as objective function. When the sixth criterion is an objective, the variant 1 has a score. The same results are for the criteria from 7 to 11 , when they are used as objective functions. The variant 5 has a score, when the seventh criterion is an objective function. The variant 1 has a score 1 in the cases, when the criteria S8-S11 are used individually as an objective function. The values of the matrix ERM present results in different units. Normalization of ERM is presented in Table 4. 


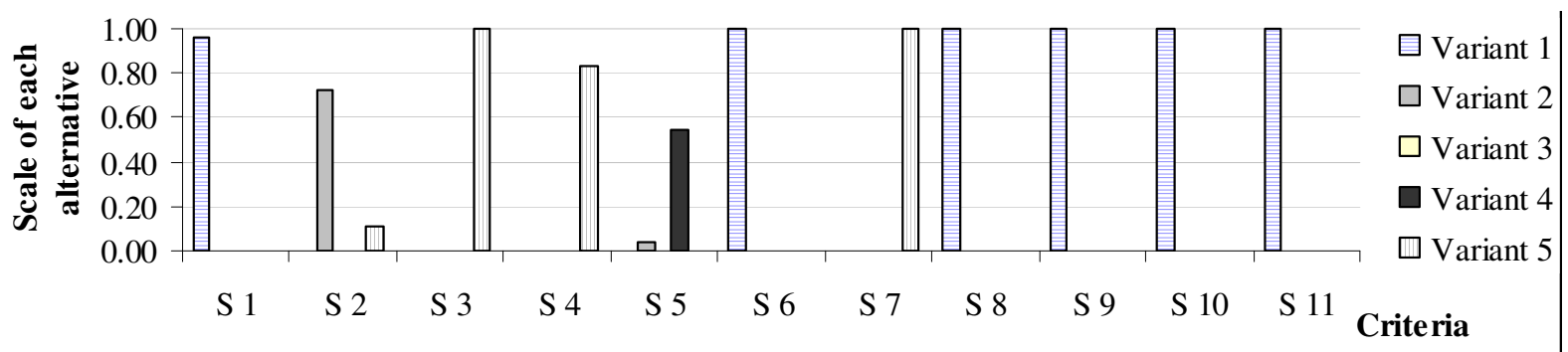

Fig. 1. Score of criteria by variants

Table 4

Efficient Results Matrix (ERM) Normalized

\begin{tabular}{|c|c|c|c|c|c|}
\hline Criteria & Variant 1 & Variant 2 & Variant 3 & Variant 4 & Variant 5 \\
\hline S 1 & 1.00 & 0.00 & 0.00 & 0.00 & 0.00 \\
\hline S 2 & 0.00 & 0.87 & 0.00 & 0.00 & 0.13 \\
\hline S 3 & 0.00 & 0.00 & 0.00 & 0.00 & 1.00 \\
\hline S 4 & 0.00 & 0.00 & 0.00 & 0.00 & 1.00 \\
\hline S 5 & 0.00 & 0.06 & 0.00 & 0.94 & 0.00 \\
\hline S 6 & 1.00 & 0.00 & 0.00 & 0.00 & 0.00 \\
\hline S 7 & 0.00 & 0.00 & 0.00 & 0.00 & 1.00 \\
\hline S 8 & 1.00 & 0.00 & 0.00 & 0.00 & 0.00 \\
\hline S 9 & 1.00 & 0.00 & 0.00 & 0.00 & 0.00 \\
\hline S 10 & 1.00 & 0.00 & 0.00 & 0.00 & 0.00 \\
\hline S 11 & 1.00 & 0.00 & 0.00 & 0.00 & 0.00 \\
\hline Sum of Column (SC) & 6.00 & 0.93 & 0.00 & 0.94 & 3.13 \\
\hline Participation Factor (PF) & 6 & 2 & 0 & 1 & 4 \\
\hline $\begin{array}{c}\text { Normalized Participation } \\
\text { Factor (NPF) }\end{array}$ & 0.55 & 0.18 & 0.00 & 0.09 & 0.36 \\
\hline Final Result (SC x NPF) & 3.27 & 0.17 & 0.00 & 0.09 & 1.14 \\
\hline ERM Ranking & Variant 1 - Variant 5 - Variant 2 - Variant 4 - Variant 3 \\
\hline
\end{tabular}

It can be seen that the variant 1 satisfies six criteria, variant 2 satisfies two criteria, variant 5 satisfies four criteria, and variant 4 satisfies only one criterion. Variant 3 does not meet any criteria. This is shown in the Participation Factor (PF). The maximal score of the Sum of Column (SC) has variant 1. The Normalized Participation Factor (NPF) has maximal value for variant 1 . This factor is calculated taking into account that the total number of criteria is 11 . The ERM ranking is presented in the last row in Table 4. The ranking is Variant 1 - Variant 5 - Variant 2 - Variant 4 - Variant 3.

Table 5 presents the squared Project Dominance Matrix (PDM). The number of columns and the rows in this matrix is equal to the number of variants. The net dominance is presented in the last column of the table. The variant 1 has the dominance value of 24 and subordinate value of 5 . The maximal score of net dominance presents the best variant. The variant 1 has the greatest value of the net dominance.

The PDM ranking is shown in the last row of the table. It can be seen that the ranking by ERM and PDM is closed. As the values of net dominance for Variant 2 and Variant 4 are equal, two rankings can be made. It can be seen that the rating by both ways is equal.

Table 5

Project Dominance Matrix (PDM)

\begin{tabular}{|c|c|c|c|c|c|c|c|}
\hline \multicolumn{7}{|c|}{ Subordinated variants - alternatives - options } & Row sum of \\
Dominant variant & $\begin{array}{c}\text { Variant } \\
\text { dominant } \\
\end{array}$ & $\begin{array}{c}\text { Variant } \\
\text { variant }\end{array}$ & $\begin{array}{c}\text { Variant } \\
\text { Net } \\
\text { dominance }\end{array}$ \\
\hline Variant 1 & - & 6.0 & 6.0 & 6.0 & 6.0 & 24.0 & 19.0 \\
\hline Variant 2 & 0.9 & - & 0.9 & 0.9 & 0.8 & 3.5 & -6.3 \\
\hline Variant 3 & 0.0 & 0.0 & - & 0.0 & 0.0 & 0.0 & -11.0 \\
\hline
\end{tabular}


Table 5 (continued)

\begin{tabular}{|c|c|c|c|c|c|c|c|}
\hline \multicolumn{6}{|c|}{ Subordinated variants - alternatives - options } & \multirow{2}{*}{$\begin{array}{c}\text { Row sum of } \\
\text { dominant } \\
\text { variant }\end{array}$} & \multirow[b]{2}{*}{$\begin{array}{c}\text { Net } \\
\text { dominance }\end{array}$} \\
\hline Dominant variant & $\begin{array}{c}\text { Variant } \\
1 \\
\end{array}$ & $\begin{array}{c}\text { Variant } \\
2 \\
\end{array}$ & $\begin{array}{c}\text { Variant } \\
3\end{array}$ & $\begin{array}{c}\text { Variant } \\
4\end{array}$ & $\begin{array}{c}\text { Variant } \\
5\end{array}$ & & \\
\hline Variant 4 & 0.9 & 0.9 & 0.9 & - & 0.9 & 3.7 & -6.3 \\
\hline Variant 5 & 3.1 & 3.0 & 3.1 & 3.1 & - & 12.4 & 4.7 \\
\hline $\begin{array}{l}\text { Column Sum of } \\
\text { subordinated } \\
\text { variants }\end{array}$ & 5.0 & 9.9 & 11.0 & 10.0 & 7.7 & - & - \\
\hline PDM Ranking & \multicolumn{7}{|c|}{ Variant 1 - Variant 5 - Variant 4 - Variant 2 - Variant 3} \\
\hline
\end{tabular}

\section{Strategy 2}

This strategy uses the weights of criteria. The values of the criteria are determined by the author in [15] applying the DEMATEL method. The initial matrix is the same of this one presented in Table 1. Table 6 shows the normalized sum matrix (LHS). The values of this matrix are determined by multiplication the LHS matrix given in Table 2 by weights of criteria that are given in the last column of Table 6. The values of the normalized Efficient Results Matrix (ERM) and Project Dominance Matrix (PDM) of Strategy 2 are the same with these of Strategy 1. Figure 2 and Figure 3 present the comparison of the results for both strategies according to the type of ranking. It can be seen that variant 1 , which shows the carriage of freight block trains by direction Sofia-Gorna OryahovitsaVarna, is the best variant.

Table 6

Normalized "Sum" Matrix (LHS)

\begin{tabular}{|c|c|c|c|c|c|c|c|}
\hline Criteria & Variant 1 & Variant 2 & Variant 3 & Variant 4 & Variant 5 & RHS & Weight \\
\hline S 1 & 0.01 & 0.01 & 0.02 & 0.02 & 0.02 & 0.01 & 0.08 \\
\hline S 2 & 0.03 & 0.03 & 0.04 & 0.05 & 0.04 & 0.03 & 0.19 \\
\hline S 3 & 0.05 & 0.05 & 0.00 & 0.00 & 0.00 & 0.00 & 0.09 \\
\hline S 4 & 0.03 & 0.03 & 0.00 & 0.00 & 0.00 & 0.00 & 0.07 \\
\hline S 5 & 0.03 & 0.03 & 0.02 & 0.03 & 0.03 & 0.02 & 0.13 \\
\hline S 6 & 0.02 & 0.02 & 0.02 & 0.02 & 0.02 & 0.02 & 0.12 \\
\hline S 7 & 0.03 & 0.03 & 0.00 & 0.00 & 0.00 & 0.00 & 0.06 \\
\hline S 8 & 0.02 & 0.02 & 0.02 & 0.02 & 0.02 & 0.02 & 0.08 \\
\hline S 9 & 0.04 & 0.04 & 0.00 & 0.00 & 0.00 & 0.04 & 0.07 \\
\hline S 10 & 0.03 & 0.03 & 0.00 & 0.00 & 0.00 & 0.03 & 0.05 \\
\hline S 11 & 0.02 & 0.02 & 0.00 & 0.00 & 0.00 & 0.02 & 0.04 \\
\hline
\end{tabular}

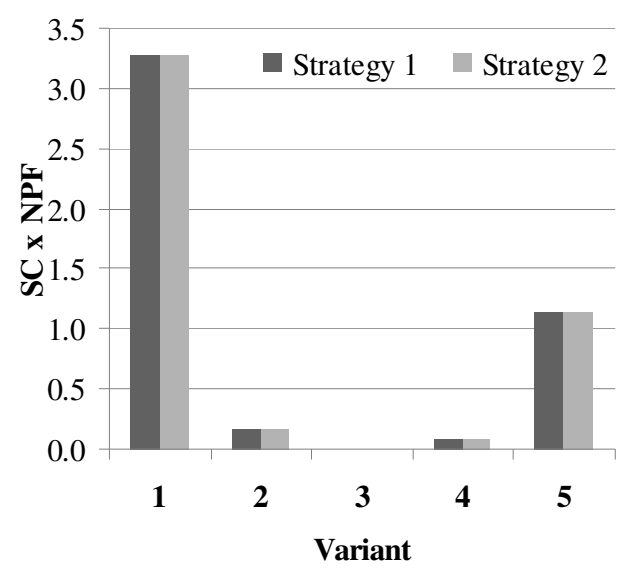

Fig.2. Comparison of ERM Ranking

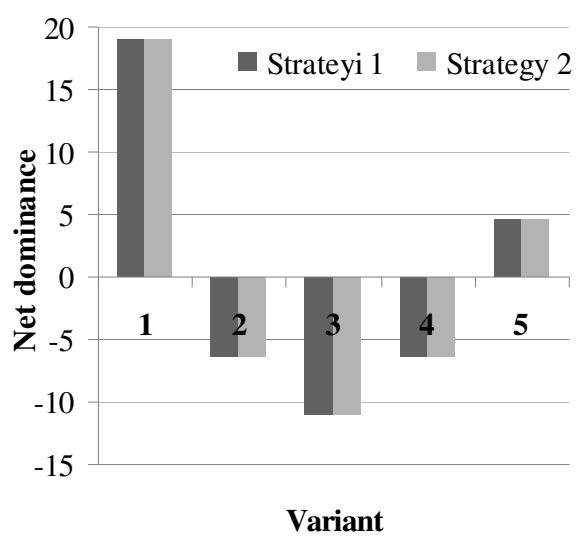

Fig.3. Comparison of PDM Ranking 


\section{Conclusions}

1. In this research a methodology has been elaborated based on application of the SIMUS method for assessment of alternative transport policies for container carriage. This method is based on linear optimization and helps decision makers make objective decisions based on mathematical formalization.

2. Two strategies of SIMUS application have been experimented. The first strategy does not use the weights of criteria, and the second one applies the weights of criteria in SIMUS optimization. It was found that application of the weights of criteria into mathematical model of SIMUS procedure does not affect the change in the results. This proves the important advantage of application of the SIMUS method not to use subjective assessments of experts to determine the weights of criteria.

3. The rating of the alternatives by the Efficient Results Matrix and Project Dominance Matrix is equal.

4. Based on linear programming that is used in the SIMUS method, we have determined the solution for each criterion defined in the study as objective function. The variant 1 with railway transportation and carriage of containers by block trains has the maximal number of SIMUS criteria score different from 0 . It was found that this variant satisfies the following criteria: S1: Environmental criterion; S6: Transport from door to door; S8: Comfort; S9: Security; S10: Reliability and S11: Stability. In the second position is variant 5, in which road transport is used. In this case the following four criteria have been satisfied: S2: Operational costs for intermodal transportation; S3: Transportation fare; S4: Infrastructure charges; S7: Duration of transhipment operations. Variant 3, in which also road transport is used, does not meet any criteria. It was found that the optimal is the variant whit the maximal number of SIMUS criteria score. It was found that the carriage of containers by block trains is the best transportation policy.

5. The methodology could be used to study different transport polices for intermodal carriage.

\section{Acknowledgements}

This research has been supported by the contract No.KП-06-H27/12 of 11.12.2018 "Modelling and elaboration of complex system for selection of transport technology in transport network" funded by the National Science Fund of the Ministry of Education and Science of Bulgaria.

\section{References}

[1] Teng L., Zhang Z.Container multimodal transport routing selection modeling considering carbon emission cost.Proceedings of "International Conference on Logistics, Informatics and Service Sciences (LISS)“", 27-29 July 2015,Barcelona, Spain, doi: 10.1109/LISS.2015.7369770.

[2] Zhang Q., Cui M., Ye J., DongH., Zhuang Y., Yang H.; Wei Y.Study on the optimization of route selection for container multimodal transport based on the time value. Advances in Transportation Studies,Special Issue, vol. 3,2017, pp. 49-60.

[3] Hao C., Yue Y. Optimization on Combination of Transport Routes and Modes on Dynamic Programming for a Container Multimodal Transport System. Procedia Engineering, vol. 137, 2016, pp.382-390. doi: 10.1016/j.proeng.2016.01.272.

[4] Balakrishnan A., Karsten CV. Container shipping service selection and cargo routing with transshipment limits. European Journal of Operational Research, vol.263, 2017, pp. 652-663. doi.org/10.1016/j.ejor.2017.05.031.

[5] Winebrake J., Corbett J., Falzarano, A., Hawker J. S., Korfmacher K., Ketha S.,Zilora S.Assessing energy, environmental,and economic tradeoffs in intermodal freight transportation. Journal of the Air \&Waste Management Association, vol.58(8), 2008, pp. 1004-1013. doi.org/10.3155/1047-3289.58.8.1004.

[6] Gohari A., Matori A. N., Khamaruzaman W. Toloue Y I., Myint K C., Sholagberu A T. Route/Modal choice analysis and tradeoffs evaluation of the intermodal transport network of Peninsular Malaysia. Cogent Engineering, vol.5: 1436948, 2018, doi.org/10.1080/23311916.2018.1436948.

[7] Nan Y., Zhehui Z.,Shuhui Z. Optimization for Time-limited Intermodal Transportation Route Selection Considering Carbon Emission Costs. Advances in Engineering Research, vol.123, 2017, pp. 318-324. 
[8] Sun Y., Lang M. Bi-objective Optimization for Multi-modal Transportation Routing Planning Problem Based on Pareto Optimality. Journal of Industrial Engineering and Management, vol. 8(4), 2015, pp. 1195-1217, .doi.org/10.3926/jiem.1562.

[9] Elifcan G., Rizvan E. The Problem of Sustainable Intermodal Transportation: A Case Study of an International Logistics Company, Sustainability, vol. 10, 4268, 2018, doi:10.3390/su10114268.

[10] Islam D.M. Z., Zunder T., Jorna R. Performance evaluation of an online benchmarking tool for European freight transport chains. Benchmarking: An International Journal, vol. 20, Issue: 2, 2013, pp. 233-250.

[11] Abramovic B., Zitricky V., Biskup V. Organisation of railway freight transport: case study CIM/SMGS between Slovakia and Ukraine, European Transport Research Review, vol. 8(4), 2016, p. 27.

[12] Abramovic B., Lovric I., Supalo V. Analysis of intermodal terminals service quality in the republic of Croatia, Promet- Traffic\&Transportation, vol. 24, no. 3, 2012, pp. 253-260.

[13] Skrucany T., Ponicky J., Kendra M., Gnap J. Comparison of railway and road passenger transport in energy consumption and GHG production, Proceedings of the "Third international conference on traffic and transport engineering (ICTTE)", Belgrade, 24-25 November, 2016, pp. 744-749.

[14] Camaj J., Masek J., Kendra M. Possibility of applying the common queue of waiting for servicing railway passengers. Proceedings of the "19th Scientific Conference on Transport Means", January, 2015, pp. 147-151.

[15] Stoilova S., Kunchev L. Study of criteria for evaluation of transportation with intermodal transport. Proceedings of 16th International Scientific Conference Engineering for Rural Development, May24-26, 2017, Jelgava, Latvia, pp. 349-357. doi:10.22616/ERDev2017.16.N070

[16] Szücs, G. Route planning based on uncertain information in transport networks, Transport, vol. 27(1), 2012, pp. 79-89.

[17] Kunchev L. Methodology for selection the optimal route and transport for carriage of containers. Proceedings of 22nd International Scientific Conference. Transport Means, 2018, pp. 724-728.

[18] Kengpol A.,W. Tuominen M.M. The development of a decision support system in multimodal transportation routing within Greater Mekong sub-region countries, International Journal of Production Economics, vol. 140 (2), 2012, 691 p.

[19] Podvezko V., Sivilevičius H. The use of AHP and rank correlation methods for determining the significance of the interaction between the elements of a transport system having a strong influence on traffic safety, Transport, vol.28(4), 2013, 389 p.

[20] Stoilova S. Methodology for Multi-criteria Selection of Transportation Technology in Transport Network. In: Sładkowski A. (eds) Modelling of the Interaction of the Different Vehicles and Various Transport Modes. Lecture Notes in Intelligent Transportation and Infrastructure. Springer, Cham, 2020. doi.org/10.1007/978-3-030-11512-8_1.

[21] Pencheva V., Asenov A., Grozev D., Angelova R. Georgiev I. Analysis of the traffic intensity of cargo vehicles in the border points. Katowice. Poland. Transport problem, vol.13, Issue 4, 2018 , pp. 23-36.

[22] Pencheva V., Asenov A., Sładkowski A., Georgiev I., Beloev I., Ivanov K. The Danube River, Multimodality and Intermodality. In: Sładkowski A. (eds) Modelling of the Interaction of the Different Vehicles and Various Transport Modes. Lecture Notes in Intelligent Transportation and Infrastructure. Springer, Cham, 2020. doi.org/10.1007/978-3-030-11512-8_6.

[23] Martinov S. Evaluation model of railway infrastructure potential for establishment of freight intermodal terminals, Proceedings of the 5th International Conference on Road and Rail Infrastructures - CETRA 2018, pp. 911-916.

[24] Munier N. Astrategy for using multicriteria analysis in decision-making.Springer, 2011, 298 p., doi 10.1007/978-94-007-1512-7.

[25] Munier N. A new approach to the rank reversal phenomenon in MSDM with the SIMUS method. Multiple criteria decision making. Vol.11. 2016, pp.137-152.doi 10.22367/mcdm.201.11.09.

[26] Software SIMUS System.[online] [01.03.2019]. Available at: https://sites.google.com/site/decisionmakingmulticriteria/software-simus-system.

[27] Stoilova S. Evaluation efficiency of intermodal transport using multi-criteria analysis. Engineering for Rural Development, Proceedings of 17th International Scientific Conference Engineering for Rural Development, ERD 2018, Jelgava, Latvia,May23-25, 2018, vol.17, pp. 2030-2039, Code 137032,doi: 10.22616/ERDev2018.17.N246. 